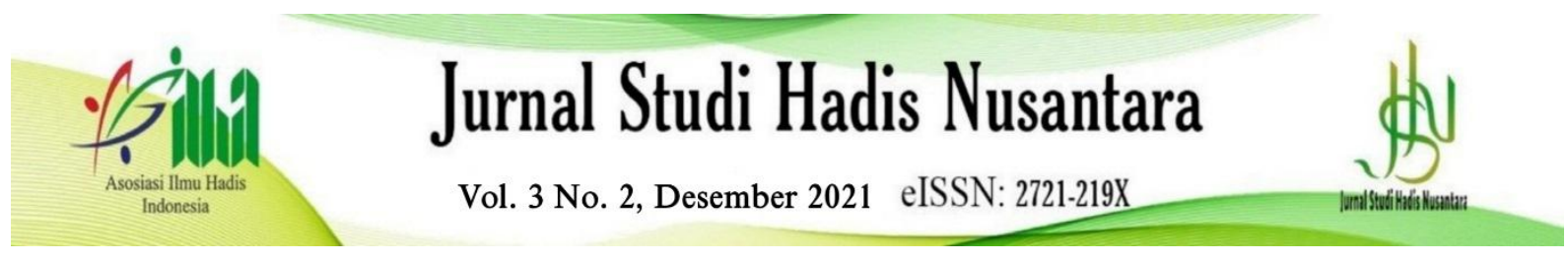

\title{
Living Hadis Tradisi Baburu Kandiak Pada Masyarakat Minangkabau
}

\author{
Bunga Fitria Febriyanti \\ UIN Sunan Kalijaga Yogyakarta \\ bfitria23@gmail.com
}

\begin{abstract}
Abstrak
Penelitian ini mengenai tradisi baburu kandiak di Minangkabau, Kecamatan Sungai Pua, Kabupaten Agam, Sumatera Barat. Penelitian ini bertujuan mengetahui hadis-hadis yang dijadikan pijakan dalam berburu dan untuk mengetahui peran hadis serta impilaksi hadis dalam proses berburu pada tradisi Minangkabau. Penelitian ini merupakan jenis penelitian kualitatif. Pengumpulan data dilakukan dengan observasi partisipasi serta wawancara. Hasil penelitian menunjukkan berburu dengan anjing menjadi kebiasaan masyarakat Minangkabau khususnya daerah Kecamatan Sungai Pua, Kabupaten Agam, Sumatera Barat. Anjing yang dipelihara diperlakukan dengan baik untuk menjaga rumah, ternak, sawah, ladang, serta digunakan sebagai hewan pemburu babi yang merusak lahan pertanian serta pemukiman penduduk. Kegiatan berburu babi dilakukan oleh laki-laki baik muda maupun paruh baya, dari perdesaan maupun perkotaan. Objek buruan adalah binatang-binatang yang meresahkan dan merugikan masyarakat disektor pertanian dan perkebunan seperti babi hutan. Simpulan penelitian menunjukan masyarakat Minangkabau tidak melandaskan aktivitas tradisi baburu kandiak pada hadis Nabi Muhammad SAW. Internalisasi nilai hadis terhadap tradisi berburu pada masyarakat Minangkabau adalah warga yang beragama Islam tidak memakan babi hasil buruan. Hewan buruan dimakan oleh anjing pemburu. Hadis Nabi Muhammad SAW menjelaskan berburu menggunakan anjing dibolehkan, namun ada syarat yang harus dipenuhi. Beberapa ulama berpendapat, hasil buruan harus dibersihkan terlebih dahulu dengan air hingga tujuh kali. Ulama lain berpendapat hasil buruan tidak perlu dicuci dan halal untuk dimakan. Baburu kandiak di Minangkabau tidak digunakan untuk dikonsumsi, melainkan untuk melindungi kawasan pertanian dari hama babi hutan. Fungsi manifes baburu kandiak sebagai berikut: Pertama, gotong royong membasmi hama babi; Kedua, olahraga dan menjaga kesehatan; Ketiga, rekreasi dan wisata.
\end{abstract}

Kata Kunci: Berburu, Baburu Kandiak, Hadis, Minangkabau 


\begin{abstract}
This research is about the tradition of the baburu kandiak in Minangkabau, Sungai Pua District, Agam Regency, West Sumatra. This study aims to determine the traditions used as a basis for hunting and to determine the role of hadith and the implications of hadith in the hunting process in the Minangkabau tradition. This research is a type of qualitative research. Data was collected using participatory observation and interviews. The results showed that hunting has become a habit of the Minangkabau people, especially the Sungai Pua District, Agam Regency, West Sumatra. Dogs that are kept well to guard homes, livestock, rice fields, fields, and are used as hog hunting animals that damage land and human settlements. Pig hunting activities are carried out by both young and middle-aged men, from rural and urban areas. Hunted objects are animals that are disturbing and detrimental to the community in the agricultural and plantation sectors such as wild boars. The conclusion of the study shows that the Minangkabau people do not base their activities on the tradition of Babur Kandiak on the hadith of the Prophet Muhammad SAW. The internalization of the value of hadith on traditional hunting in the Minangkabau community is that people who are Muslim do not eat hunted pigs. Game animals are eaten by hunting dogs. The hadith of the Prophet Muhammad SAW explains that hunting using dogs is permissible, but there are conditions that must be met. Some scholars are of the opinion that the prey must first be cleaned with air up to seven times. Other scholars are of the opinion that hunting is unnecessary and halal to eat. Baburu Kandiak in Minangkabau is not used for food, but to protect agricultural areas from wild boar pests. The manifest functions of Baburu Kandiak are as follows: First, mutual cooperation to eradicate pig pests; Second, exercise and maintain health; Third, recreation and tourism.
\end{abstract}

Keyword: Hunting, Baburu Kandiak, Hadith, Minangkabau

\section{PENDAHULUAN}

Dalam memenuhi kebutuhan hidupnya, manusia melakukan beberapa usaha seperti berburu binatang. Beberapa alasan manusia berburu seperti memenuhi kebutuhan pangan, menyalurkan hobi, berolahraga, dan membasmi binatang yang menjadi hama tanaman pertanian dan perkebunan (babi, tikus dan gajah). AlQur'an menerangkan tentang halal dan haramnya binatang, boleh tidaknya berburu, serta alat yang digunakan untuk berburu. Al-Hadis juga menerangkan halal-haramnya binatang, binatang yang boleh diburu, serta alat-alat yang boleh digunakan untuk berburu. Al-Qur'an dan Hadis memberikan legitimasi kebolehan umatnya untuk berburu disertai dengan syarat-syarat. Hal ini penting diatur karena banyak dari manusia menggantungkan hidupnya dari berburu. Bahkan ahli fikih pun membuat bab tersendiri tentang berburu. Mereka menguraikan mana yang halal dan mana yang haram, mana yang wajib dan mana yang sunah.

Realitas diatas menarik untuk diteliti tentang peran hadis berburu serta internalisasi nilai-nilai hadis terhadap berburu untuk kehidupan dalam 
masyarakat Minangkabau. Internalisasi nilai-nilai melalui pemahaman hadis secara utuh, diteruskan dengan pentingnya kesadaran mempelajari hadis, serta ditemukannya posibilitas merealisasikannya dalam kehidupan nyata. Sudah banyak penelitian tentang berburu namun belum ada yang meneliti bagaimana berburu dalam prespektif hadis. Oleh karena itu, penelitian ini sangat perlu dan menarik untuk dikaji. Rumusan masalah dalam penelitian ini adalah bagaimana hadis menjelaskan tradisi berburu kandiak dalam masyarakat Minangkabau? Tujuan penelitian ini yaitu ingin mengetahui hadis-hadis yang dijadikan pijakan dalam berburu serta mengetahui peran dan implikasi hadis dalam proses berburu pada tradisi masyarakat Minangkabau.

\section{Metode Penelitian}

Penelitian menggunakan metode penelitian kualitatif. ${ }^{1}$ Peneliti menganalisis suatu peristiwa atau kejadian yang terjadi di lapangan sebagaimana adanya. Peneliti menggunakan sumber data primer dan sekunder. Teknik pengumpulan data melalui observasi partisipasi, wawancara, dan dokumentasi. Data yang dikumpulkan diolah dengan cara reduksi data, verifikasi data, menyajikan data, lalu ditarik kesimpulan dan dianalisis secara kualitatif, kemudian dilakukan uji keabsahan data dengan uji kredibilitas, transferabiliti, realibilitas, kemudian komfirmabiliti. ${ }^{2}$

Living hadis merupakan resepsi suatu komunitas muslim yang didasarkan

\footnotetext{
1 Dona Kahfi, "Tradisi Mandi Balimau di Masyarakat Kuntu" dalam Jurnal Living Hadis, Volume 1, Nomor 2, Oktober 2016
}

dari sebuah hadis, baik individu maupun komunal. Kajian living hadis berkaitan dengan fenomena praktik, tradisi, ritual, atau prilaku yang hidup di masyarakat yang landasannya hadis Nabi. Secara antropologis, living hadis atau "hadis yang hidup" memandang peristiwa ini sebagai fenomena sosial budaya, yaitu sebagai sebuah gejala yang berupa pola-pola prilaku individu-individu yang muncul dari dasar pemahaman mereka mengenai hadis. Fenomena yang menjadi objek kajian bukan lagi hadis sebagai kitab tetapi perlakuan manusia terhadap hadis dan bagaimana pola-pola prilaku yang dianggap berdasarkan atas pemahaman tentang hadis itu diwujudkan. ${ }^{3}$

\section{Hasil Penelitian}

\section{A. Pengertian Berburu}

Berburu secara bahasa ash-shahid merupakan hal yang halal dan baik namun dimubahkan oleh Allah SWT untuk kita memakannya. Hewan buruan adalah hewan yang ditangkap dari jenis hewan yang boleh dimakan daging nya, namun dengan syarat-syarat yang telah ditentukan. Berburuh hukumnya boleh (mubah), jika tidak mendatangkan kemudharatan bagi manusia. Buruan yang dimubahkan adalah buruan yang ditangkap berdasarkan tujuan menyembelihnya, jika tidak maka hukumnnya haram. Rasullah SAW juga melarang membunuh hewan kecuali untuk dimakan.

\footnotetext{
${ }^{2}$ Sugiyono, Metode Penelitian Pendidikan Pendekatan Kualitatif, Kuantitatif, dan R\&D

3 Saifuddin Zuhri Qudsy, "Living Hadis Genealogi, Teori dan Aplikasi" dalam Jurnal Living Hadis, Volume 1, Nomor 1, Mei 2016
} 


\section{B. Dasar Hukum Berburu}

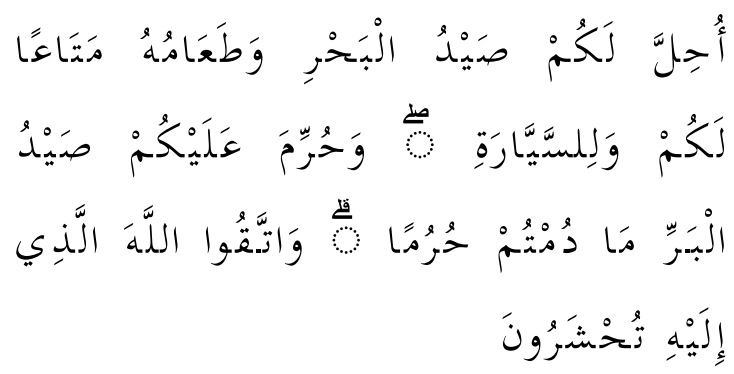

Artinya : "Dihalalkan bagimu binatang buruan laut dan makanan (yang berasal) dari laut sebagai makanan yang lezat bagimu, dan bagi orang-orang yang dalam perjalanan; dan diharamkan atasmu (menangkap) binatang buruan darat, selama kamu dalam ihram. Dan bertakwalah kepada Allah Yang kepadaNya-lah kamu akan dikumpulkan".

Berburu hukumnya adalah mubah apabila daging buruan bisa dipakai untuk dikonsumsi dan hukumnya sunah apabila dipakai untuk kelangsungan hidup dalam keadaan darurat. Berburu akan berubah menjadi makruh jika hanya di lakukan untuk senang-senang atau main-main. Berburu haram jika dilakukan hanya untuk menyiksa atau menganiaya binatang buruan tersebut.

Ulama mazhab Syafi'i mengatakan bahwa hasil buruan yang telah gigitan anjing itu haram dan harus dibersihkan sebanyak tujuh kali terlebih dahulu dengan menggunakan air yang sudah dicampur dengan tanah sehingga hewan buruan tersebut menjadi halal dan suci. Ulama mazhab Maliki dan mahzab Hambali mengatakan bekas gigitan anjing adalah halal dan boleh dimakan tanpa harus mencucinya terlebih dahulu, sehingga secara garis besar hewan buruan tersebut merupakan hewan halal menurut Islam untuk dikonsumsi namun dengan syarat jika hewan berburu sudah terlatih. ${ }^{3}$

\section{Berburu dalam Hadis}

Aktifitas berburu babi pada masyarakat Minangkabau khusus dilakukan oleh kaum laki-laki saja. Alat yang digunakan masyarakat untuk berburu adalah anjing, sebagaimana hadis yang menjelaskan sebagai berikut:

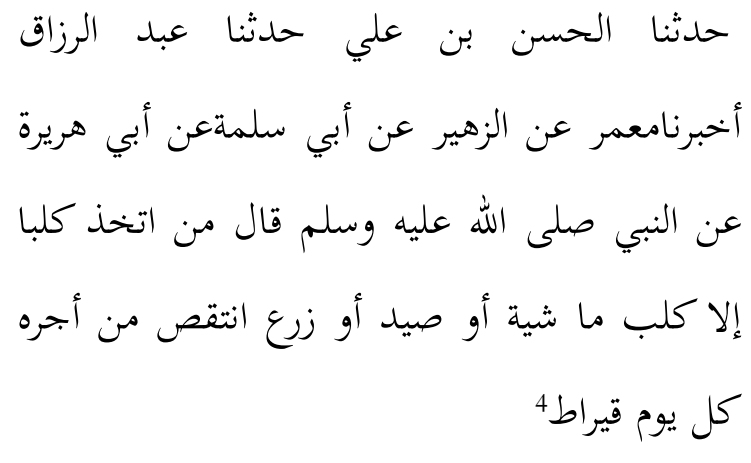

Artinya: Telah menceritakan kepada kami Al Hasan bin Ali, telah menceritakan kepadakami Abdurrazzaq, telah mengabarkan kepada kami Ma'mar, dari Az Zuhri, dari Abu Salamah, dari Abu Hurairah, dari Nabi shallallahu 'alaihi wasallam, beliau berkata: "Barangsiapa yang memelihara anjing kecuali anjing penjaga binatang ternak atau anjing peburu, atau penjaga tanaman maka pahalanya berkurang satu Qirath setiap hari."

Ibnu Abdil Barr mengatakan, hadis ini menunjukkan bolehnya memelihara anjing untuk berburu, menjaga ternak, dan menjaga tanaman. Jadi, hukumnya makruh bila tanpa keperluan serupa itu, karena memelihara anjing bisa menyulitkan

\footnotetext{
${ }^{3}$ Tika Novrianti Wahyuni, Skripsi,"Hukum Berburu Binatang Menggunakan Senjata Api Dan Mengkonsumsinya Dalam Persepektif Islam" (Lampung: UIN Raden Intan,2020) hlm 41

${ }^{4}$ Sulaiman bin al-Ash'at bin Shidad bin Amr alAzdi Abu Daud Sijistani, Sunan Abi Daud, (Naula Kasyur: Muthoba'ah Naula Kasyur, 1305 H), juz 8, h. 409
} 
manusia dan menghalangi malaikat untuk masuk ke dalam rumah. Dari penjelasan hadis diatas dapat dipahami bahwa setiap perbuatan telah diatur oleh hadis, termasuk dalam berburu dan memelihara anjing.

\section{Hadis Jami' At-Tirmidzi No. 1390}

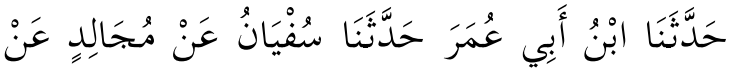
الشَّْْبِِِ عَنْ عَدِيِّ بْنِ حَاتِمٍ قَالَ سَأَلْتُ رَسُولَ اللَّهِ

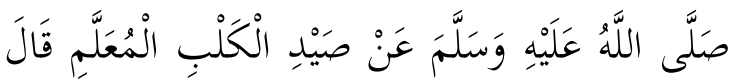
إِذَا أَرْهَلْتَ كَلْبَكَ الْمُعَلَّمَ وَذَكَرْتَ اسْمَ اللَّهِ فَكُلْ مَا

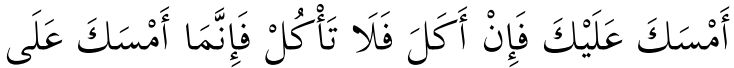
نَفْسِهِ قُلْتُ يَا رَسُولَ اللَّهِ أَرَأَيْتَ إِنْ خَالَطَتْ كِاََبَنَا

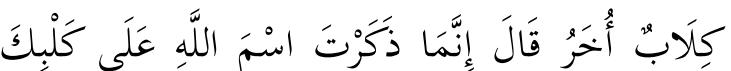
وَلََمْ تَذْكُرْ عَلَى غَيْرِهِ قَالَ سُفْيَانُ أَكْرَهُ لَهُ أَكْلَلُ

Telah menceritakan kepada kami Ibnu Abu Umar, telah menceritakan kepada kami Sufyan dari Mujalid dari Asy Sya'bi dari 'Adi bin Hatim ia berkata; Aku bertanya kepada Rasulullah shallallahu 'alaihi wasallam tentang berburu dengan anjing terlatih. Beliau menjawab: "Jika engkau mengutus anjingmu yang terlatih dan menyebut nama Allah, maka makanlah apa yang ditangkapkan untukmu. Jika ia memakannya maka janganlah engkau memakannya, karena ia menangkap untuk dirinya." Aku bertanya; Wahai Rasulullah, jika anjing kami bercampur dengan anjing lain? Beliau menjawab: "Sesungguhnya engkau menyebut nama Allah untuk (melepas) anjingmu dan engkau tidak menyebutnya (asma Allah, basmalah) untuk yang lain." Sufyan berkata; Aku memakruhkan untuk memakannya.

Abu Isa berkata; "hadis ini menjadi pedoman amal menurut sebagian ulama dari kalangan sahabat Nabi shallallahu 'alaihi wasallam dan selain mereka tentang hewan buruan dan sembelihan jika jatuh ke dalam air agar tidak memakannya". Abdullah bin Al Mubarak berpendapat tentang hewan sembelihan; "Jika terpotong tenggorokannya lalu jatuh ke dalam air dan mati maka ia dimakan". Sedangkan para ulama berselisih tentang anjing yang memakan hewan buruan, Sufyan dan Abdullah bin Al Mubarak, Asy Syafi'i, Ahmad dan Ishaq, berpendapat "Jika anjing itu makan darinya maka jangan engkau makan". Ini menjadi pendapat namun sebagian ulama dari kalangan sahabat Nabi shallallahu 'alaihi wasallam dan selain mereka membolehkan makan darinya meskipun anjing memakan darinya ${ }^{5}$.

Ada beberapa prasyarat berburu menggunakan binatang, baik anjing atau burung elang, sebagai berikut.

1. Binatang tersebut harus di ajar (dilatih) oleh tuannya. Jika anjing itu dipanggil maka dia akan bertahan dan kalau di usir ia akan pergi.

2. Binatang tersebut harus memburu buruan untuk tuannya. Maksud menangkap atau memburu untuk tuannya ialah binatang tersebut tidak memakan binatang hasil buruannya. Jika ia memakannya berarti buruan tersebut tidak halal.

\footnotetext{
5 Anjing Menyantap buruan (https://www.hadits.id/hadits/tirmidzi/1390, diakses pada tanggal 22 April 2021 pukul 15:13).
} 
3. Menyebut nama Allah ketika hendak melepaskannya. Menyebut asma Allah ketika hendak melepaskan panah, tombak, atau memukulkan pedang. Hal ini berdasarkan Al-Qur'an dan AlHadis terdahulu. Jika lupa menyebut nama Allah ketika melepaskannya, maka susullah menyebut nama Allah ketika hendak memakannya, sebagaimana dilakukan dalam hal penyembelihan.

\section{Tradisi Baburu Kandiak di Minangkabau}

Baburu kandiak adalah tradisi yang dilakukan oleh masyarakat Minangkabau dengan memanfaatkan hewan buruan anjing. Anjing merupakan hewan yang memiliki indra penciuman sangat tajam. Kemampuan anjing tersebut dapat dengan mudah mendeteksi keberadaan babi hutan. Kecepatan lari seekor anjing, rahang, dan kuku yang tajam dapat digunakan untuk menerkam babi hutan. Masyarakat Minangkabau menganggap berburu kandiak akan lebih mudah dilakukan dengan seekor anjing dari pada tombak maupun panah.

Tradisi baburu kandiak tidak hanya dilakukan oleh masyarakat Minangkabau. Beberapa masyarakat yang tinggal di daerah yang berbatasan langsung dengan area hutan juga melakukan baburu kandiak, seperti suku Ayapo di Sentani Papua, masyarakat Flores Nusa Tenggara, dan masyarakat Bengkulu Tengah. Namun, hal ini berbeda dengan tradisi berburu di Minangkabau. Hasil baburu kandiak tidak untuk dimakan karena mayoritas masyarakat Minangkabau menganut agama
Islam. Mereka memegang teguh semboyan yang berbunyi "Adat Nan Basandi Syarak, Syarak Basandi Kitabullah". Baburu kandiak digunakan untuk membantu para petani memberantas hama babi hutan, guna melindungi usaha-usaha petani di area pertanian mereka. ${ }^{6}$

Baburu kandiak telah dilakukan masyarakat Minangkabau secara turun temurun sejak nenek moyang. Kini baburu kandiak dianggap sebagai permainan rakyat. Pepatah Minangkabau meyebutkan "berburu babi suntiang niniak mamak pamenan dek nan mudo dalam nagari”. Makna dari pepatah tersebut adalah kebanggaan bagi niniak mamak dan salah satu permainan bagi kaum muda. Penggemar permainan ini begitu banyak. Berasal dari berbagai lapisan sosial dan ekonomi. Dari kalangan atas sampai bawah, baik pedagang, pegawai, pensiunan, petani, bahkan para pelajar. Sekarang, baburu kandiak tidak hanya dilakukan orang desa saja. Orang kotapun aktif melakukan kegiatan tersebut.

Berburu tidak hanya dinikmati oleh para peserta saja, namun juga warga desa. Warga yang hidup dari bertani sangat tertolong tradisi baburu kandiak. Sebab, serangan hama babi dapat teratasi. Para pedagang dari desa lain memanfaatkan situasi itu untuk bertransaksi dagang hasilhasil bumi. Sementara fungsi-fungsi lain baburu kandiak seperti olahraga dan rekreasi bagi masyarakat yang tinggal di perkotaan. Mereka menjadikan ajang baburu kandiak untuk menghilangkan kejenuhan dan lelah dari pekerjaan. Sejauh

\footnotetext{
${ }^{6}$ Syifa Ainina, "Pergeseran Fungsi Tradisi Baburu Kandiak Pada Masyarakat Nagari Pitalah Di Kabupaten Tanah Datar, Sumatra Barat". Edukasi IPS Vol.3 No.1, Maret 2019, hlm 53
} 
ini, kegiatan perburuan babi secara tradisional di Minangkabau terus berkembang.

Kini, kegiatan tradisional ini potensial dikembangkan menjadi suatu kegiatan wisata. Sejalan dengan hal tersebut, peminat kegiatan ini semakin meningkat setelah mendapat perhatian dan dukungan dari pemerintah Minangkabau. Pemerintah membentuk organisasi resmi pada tahun 1987, yaitu organisais Persatuan Olah Raga Buru Babi (PORBI). (PORBI) Persatuan Olah Raga Buru Babi merupakan organisasi yang besar. PORBI hampir terdapat di seluruh Indonesia. Anggota (PORBI) terbanyak terdapat di Sumatera, terutama di Sumatera Barat. Organisasi ini termasuk organisasi yang terorganisir yang memiliki persatuan yang sangat $\mathrm{kuat}^{7}$

Menurut pengakuan beberapa tokoh di lokasi penelitian menyebutkan bahwa permainan ini sudah sejak lama dimainkan oleh masyarakat, jauh sebelum kemerdekaan bangsa Indonesia. (Wawancara dilakukan dengan H.Ujang, usia 78 tahun pada 23 Mei 2021) mengatakan bahwa "Datuak den lah baburu juo jak den masih bamain jo kawan sebayo, beliau poi baburu basamo, den ikiuk mairik anjiang" (kakek saya sudah berburu waktu saya masih bermain dengan teman sebaya, mereka pergi berburu bersama dan saya juga ikut memegang satu ekor anjing).

Aktifitas berburu babi dilakukan seluruh laki-laki satu kampuan (kampung)

\footnotetext{
7 Bayu Gusti Hendri, "Sistem Sosial Berburu Babi Pada Masyarakat Kabupaten Kuantan Singingi" (Studi Deskriptif Persatuan Olahraga Berburu Babi). JOM FISIP Vol. 3 No. 1 Februari 2016,hlm 2
}

yang mampu pergi berburu. Lama kelamaan, aktifitas ini diikuti oleh kampuang-kampuang lain di satu kecamatan (daerah setingkat kecamatan). Akhirnya, kegiatan ini terorganisir. Dilaksanakan dalam satu kabupaten. Aktifitas berburu yang melibatkan peserta diluar kampuang disebut buru kongsi. Aktifitas berburu sebagai upaya masyarakat dalam memberantas hama babi hutan yang banyak merusak tanaman pertanian.

Pelaksanaan kegiatan berburu babi dilaksanakan pada hari-hari libur atau harihari tertentu yang dinilai dapat dilaksanakan perburuan. Perawatan anjing yang dilakukan para pengemar berburu babi agar tetap sehat dan bersih yaitu, memandikan dua kali seminggu, membawa jalan-jalan dua kali sehari, memberi vitamin serta obat khusus.

Hal yang menarik dan unik dari kegiatan ini adalah adanya kesamaan pandangan dan tujuan dari para penggemar permainan ini. Pagi setelah melakukan salat subuh, para pecandu kegiatan berburu babi bersiap berangkat menuju tempat perburuan atau lokasi undangan perburuan. Mereka berangkat menggunakan kendaraan pribadi, kendaraan umum, dan berjalan kaki bersama anjing-anjing pemburu. Setelah kegiatan perburuan dilakukan, para pemburu biasanya kembali pulang ke kampung masing-masing. Sepanjang perjalanan pulang, biasanya diisi dengan cerita-cerita kejadian di arena perburuan.

Berburu dalam tradisi Minangkabau merupakan budaya yang sudah ada sejak zaman nenek moyang. Tradisi ini masih berkembang dan 
dilestarikan hingga saat ini. Tradisi berburu kandiak di Minangkabau tidak hanya untuk hiburan semata namun juga untuk membasmi hama babi hutan, dan melindungi usaha-usaha petani di area pertanian.

\section{Internalisasi Nilai-Nilai Hadis terhadap Tradisi Baburu Kandiak dalam Masyarakat Minangkabau.}

Hadis Nabi Muhammad SAW menerangkan dalil dibolehkannya memelihara seekor anjing untuk berburu, menjaga ternak, dan menjaga tanaman. Hanya saja, termasuk dalam kategori berburu dan lainnya adalah untuk mendatangkan manfaat dan mencegah bahaya. Tradisi baburu kandiak dengan anjing pada masyarakat Minangkabau tidak diiringi dengan pengetahuan dan pemahaman hadis Nabi Muhammad SAW tentang bolehnya berburu kandiak dengan anjing. Mereka hanya menyakini bahwa tradisi ini berasal dari nenek moyang dan digunakan untuk menjaga tanaman dari gangguan hama babi.

Internalisasi nilai-nilai hadis terhadap tradis berburu pada masyarakat Minangkabau adalah mereka tidak memakan hewan babi hasil buruannya, karena masyarakat Minangkabau mayoritas beragama Islam. Hewan buruan dibiarkan dimakan oleh anjing pemburu. Fungsi manifes dari berburu babi saat ini telah semakin berkembang, yaitu sebagai berikut: Pertama, gotong royong dalam membasmi hama babi; Kedua, berburu dijadikan sebagai olahraga dan menjaga kesehatan; Ketiga, rekreasi dan wisata.

\section{Simpulan}

Masyarakat Minangkabau tidak melandaskan aktivitas tradisi baburu kandiak pada hadis Nabi Muhammad SAW. Tradisi baburu kandiak di Minangkabau merupakan kegiatan turun temurun. Bahkan baburu kandiak dianggap sebagai permain rakyat. Baburu kandiak di Minangkabau tidak digunakan untuk dikonsumsi, melainkan untuk melindungi kawasan pertanian dari hama babi hutan. Selain itu, baburu kandiak juga untuk olahraga dan rekreasi.

Hadis Nabi Muhammad SAW telah menjelaskan bahwa berburu merupakan suatu yang dibolehkan, namun ada ketentuan dan syarat-syarat yang harus dipenuhi. Ada perbedaan pandangan para ulama terkait berburu dengan seekor anjing. Beberapa ulama berpendapat, hasil buruan harus dibersihkan terlebih dahulu dengan air hingga tujuh kali. Ulama lain berpendapat hasil buruan tidak perlu dicuci dan halal untuk dimakan.

Internalisasi nilai-nilai hadis terhadap tradisi berburu pada masyarakat Minangkabau adalah warga yang beragama Islam tidak memakan babi hasil buruan. Hewan buruan dimakan oleh anjing pemburu. Fungsi manifes baburu kandiak sebagai berikut: Pertama, gotong royong membasmi hama babi; Kedua, olahraga dan menjaga kesehatan; Ketiga, rekreasi dan wisata.

\section{DAFTAR PUSTAKA}

Ainina, Syifa. "Pergeseran Fungsi Tradisional Baburu Kandiak Pada Masyarakat Nagari Pitalah Kabupaten Tanah Datar Sumatera Barat." Edukas IPS Vulome 3 nomor 1, 2019.

Hendri, Bayu Gusti. "Sistem Sosial Berburu Babi Pada Masyarakat Kabupaten Kuantan Singingi 
(Studi Deskriptif Perstuan

Olahraga Berburu Babi)." JOM

FISIP vol 3 nomor1, 2016.

Kahfi, Dona. "Tradisi Mandi Balimau di Masyarakay Kuntu." Living Hadis Volume 1 nomor 2, 2016.

Qudsy, Saifuddin Zuhri. "Living Hadis Genealogi, Tradisi dan Aplikasi ." Living Hadis Valume 1 nomor 1, 2016: 23.

Shidad, Sulaiman bin Al-Ash'at bin. Sunan Abi Daud. Muthoba'ah: Naula Kasyur, $1305 \mathrm{H}$.

Wahyuni, Tika Novrianti. "Hukum Berburu Binatang Menggunakan Senjata Api dan Mengkonsumsinya dalam Perspektif Islam."5. Lampung: UIN Raden Intan, 2020. 